\title{
DEVELOPMENT AND CHARACTERIZATION OF GASTRORETENTIVE DRUG DELIVERY SYSTEM FOR RITONAVIR TABLETS USING NATURAL POLYMERS
}

\author{
SARITHA CHUKKA, SHAYEDA SHAIK* \\ Department of Pharmaceutics, University College of Pharmaceutical Sciences, Kakatiya University, Warangal - 506009 , Telangana, India. \\ Email: drshayeda@gmail.com
}

Received: 25 January 2016, Revised and Accepted: 27 February 2017

\section{ABSTRACT}

Objective: This study involves preparation and evaluation of floating tablets of ritonavir (RN) for improving the drug bioavailability by prolongation of gastric residence time. RN is an antiretroviral agent used in the treatment of HIV and viral diseases have been taken as a model drug in this investigation because of its low biological half-life (3-5 hrs). Moreover, it is primarily absorbed from stomach.

Methods: RN floating tablets were prepared by the dry granulation technique, using guar gum and xanthan gum as polymers, sodium bicarbonate as effervescent agent, polyvinylpyrrolidone as binding agent, Dicalcium phosphate as diluents, crospovidone as swelling agent and magnesium stearate as lubricant. The prepared tablets were evaluated for various physicochemical parameters.

Results: Drug-excipient interaction studies were conducted by Fourier transform infrared spectroscopy and differential scanning calorimetry. The results suggested that there was no incompatibility between the drug and polymers. The prepared tablets were evaluated for their physical characteristics. All the parameters were within the pharmacopoeial limits. Further, tablets were also studied for their floating properties and in vitro drug release characteristics. The tablets exhibited controlled and prolonged drug release profiles. The developed formulation was found to be stable.

Conclusion: The developed floating tablets of RN exhibit prolonged release up to 12 hrs, and thus may improve bioavailability and minimize fluctuations in plasma drug concentrations.

Keywords: Ritonavir, Floating tablets, Gastric residence time, Gastroretentive drug delivery system.

(C) 2017 The Authors. Published by Innovare Academic Sciences Pvt Ltd. This is an open access article under the CC BY license (http://creativecommons. org/licenses/by/4. 0/) DOI: http://dx.doi.org/10.22159/ajpcr.2017.v10i5.17266

\section{INTRODUCTION}

For the last three decades, oral controlled release dosage forms have been developed due to their important therapeutic advantages. By the introduction of a variety of controlled delivery systems, the inconvenience of conventional tablets or capsules was overcome. This controlled release technology had made it possible to release drugs at a constant release rate for longer periods of time. However, this benefit had not satisfied a variety of important drugs that (i) are locally active in the stomach, (ii) have an absorption window in the stomach or in the upper small intestine, (iii) are unstable in the intestinal or colonic environment, or (iv) exhibit low solubilities at high $\mathrm{pH}$ values [1-3]. These limits promoted the development of gastroretentive drug delivery systems (GRDDS). GRDDS are the systems which are retained in the stomach for a longer period of time and thereby improve the bioavailability of drugs that are preferentially absorbed from the upper gastrointestinal tract.

Various approaches have been proposed to achieve gastric retention and includes co-administration of drugs or pharmaceutical excipients that influence the gastric motility pattern and thereby delay gastric emptying [4], magnetic systems [5], mucoadhesive systems [6], swelling or unfolding [7], density-controlled systems that either float on gastric contents [8] or sediment and combination systems [9].

Ritonavir ( $\mathrm{RN})$ is a protease inhibitor widely prescribed in antiretroviral regimen. It blocks the HIV protease, thereby reducing the viral load in the infected individual [10]. This drug is mainly suffers with low oral bioavailability due to degradation of $\mathrm{RN}$ by the cytochrome P450-3A4 (CYP3A4) isoenzymes in the distal intestine [11], efflux of the absorbed drug by counter transporter proteins (mainly P-glycoprotein) present in the distal intestine $[12,13]$ and is unstable at alkaline
$\mathrm{pH}$ [14]. It shows pH-dependent solubility and solution stability [15]. Moreover, it is primarily absorbed from stomach [16] and having short half-life ( 3-5 hrs). Due to these characteristics, it was selected for the development of GRDDS.

\section{METHODS}

RN was obtained as a gift sample from Novartis, Hyderabad. Guar gum, xanthan gum was purchased from Colorcon Asia Private Limited, India. Sodium bicarbonate, crospovidone, Dicalcium phosphate, magnesium stearate, and polyvinylpyrrolidone (PVP) k-30 were purchased from S. D. Fine-Chem. Ltd., Mumbai, India.

\section{Procedure for preparation of RN floating tablets}

Accurately weighed quantities (Table 1) of polymer and Dicalcium phosphate, crospovidone were taken in a mortar and mixed geometrically. To this required quantity of RN was added and mixed slightly with pestle. Accurately weighed quantity of sodium bicarbonate was taken separately in a mortar and powdered with pestle. The powder was passed through sieve No. 40 and mixed with the drug blend which was also passed through sieve No. 40 . The whole mixture was collected in a plastic bag and mixed for 3 minutes. To this PVP K30 was added and mixed for 2 minutes. The mixture equivalent to $300 \mathrm{mg}$ was compressed into tablets with $10 \mathrm{~mm}$ flat punches at a hardness of $5 \mathrm{~kg} / \mathrm{cm}^{2}$. The composition of the different formulations is shown in Table 1.

\section{Solubility studies}

The equilibrium solubility of RN was measured in $0.1 \mathrm{M}$ hydrochloric acid ( $\mathrm{pH}$ of 1.2), phosphate buffer of $\mathrm{pH} 6.8$, and $\mathrm{pH} 7.4$ to determine its solubility. Excess amounts of the drug were added to $50 \mathrm{ml}$-stoppered conical flasks $(n=3)$. The flasks were shaken mechanically at $37^{\circ} \mathrm{C} \pm 0.5^{\circ} \mathrm{C}$ 
for $24 \mathrm{hrs,} \mathrm{in} \mathrm{a} \mathrm{horizontal} \mathrm{shaker} \mathrm{(HS} 501$ Digital, IKA-Labortechnik, and Staufen, Germany). After 2 days of equilibrium, aliquots were withdrawn and filtered ( $0.22 \mu \mathrm{m}$ pore syringe filter). Then, the filtered samples were diluted with an appropriate amount of dissolution medium and assayed by ultraviolet (UV)-spectrophotometer at $210 \mathrm{~nm}$ for RN.

Drug-excipient interaction study: Differential scanning calorimetry (DSC)

DSC thermo grams were recorded on a DSC (Perkin-Elmer, New York, NY). The instrument was calibrated with an indium standard. The samples $(2-4 \mathrm{mg})$ were heated $\left(20-300^{\circ} \mathrm{C}\right)$ at a constant scanning speed $\left(10^{\circ} \mathrm{C} /\right.$ minutes) in sealed aluminum pans, using nitrogen purged gas.

\section{Fourier-transform infrared (FTIR) spectroscopy}

Drug-polymer compatibility studies were conducted using FTIR spectrophotometer (Schimadzu) by $\mathrm{KBr}$ pellet technique. IR spectrum of pure drug and polymers were seen in between 4000 and $400 \mathrm{~cm}^{-1}$.

\section{Evaluation of physicochemical properties}

The prepared tablets were evaluated for parameters such as hardness, friability, weight variation, thickness, in vitro drug release, floating lag time (FLT), total buoyancy time, and stability study.

\section{Wight variation}

A total of 20 tablets were randomly selected and were weighed using an electronic balance (Shimadzu BL-220H, Japan). Results are expressed as mean value and standard deviation (SD).

\section{Hardness test}

The hardness tests of the tablets were determined using Monsanto hardness tester (Campbell Electronics, India). For each formulation, the hardness of six tablets was determined. Hardness values are reported in $\mathrm{kg} / \mathrm{cm}^{2}$. Mean and SD values were also calculated.

\section{Thickness}

The thickness of the tablets was determined by using vernier calipers (Mitutoyo, Japan). 10 tablets from each batch were used. Mean and SD values were also calculated.

\section{Friability}

About 10 tablets were weighed and subjected for this test by using Roche friabilator (Erection instrument and engineering, Ahmadabad, India).

\section{Drug content}

About 10 tablets from each batch were taken and triturated, powder equivalent to its average weight and were transferred into a $100 \mathrm{ml}$ volumetric flask, to this $50 \mathrm{ml}$ of $0.1 \mathrm{~N} \mathrm{HCl}$ was added then shaken for 5 minutes and make the final volume with $0.1 \mathrm{~N} \mathrm{HCl}$ up to $100 \mathrm{ml}$. Then the solution was sonicated for 15 minutes and filtered, then absorbance was determined at $210 \mathrm{~nm}$ using UV/visible spectrophotometer (Elico, SL 159, India) against $0.1 \mathrm{~N} \mathrm{HCl} \mathrm{blank.}$

\section{Floating behavior}

The buoyancy property was determined by the FLT and total floating time (TFT) by placing the tablet in a $250 \mathrm{ml}$ beaker containing $0.1 \mathrm{~N} \mathrm{HCl}$ and was observed visually.

\section{In vitro dissolution studies}

In vitro drug release studies were conducted for a period of $12 \mathrm{hrs}$ using USP XXIV type-II (Paddle) dissolution apparatus (Lab India, India) at $37 \pm 0.5^{\circ} \mathrm{C}$ at $50 \mathrm{rpm}$ using $900 \mathrm{ml}$ of $0.1 \mathrm{~N} \mathrm{HCl}$ as dissolution medium. $5 \mathrm{ml}$ of sample was withdrawn in predetermined time intervals from the dissolution medium and replaced with fresh medium to maintain the sink condition. Then, the samples were analyzed for RN by UV/visible spectrophotometer (Elico, SL 159, India) at $210 \mathrm{~nm}$.

\section{Kinetic modeling of drug release profiles}

The dissolution profiles of all formulae in $0.1 \mathrm{~N} \mathrm{HCl}$ were fitted to zero-order, first-order, Higuchi [17] and Korsmeyer-Peppas kinetic models [18]. The model with the highest correlation coefficient was considered to be the best fitting one.

\section{Physical stability studies}

Physical stability studies were conducted according to International Conference on Harmonization guidelines [19]. One of the optimized formulations was placed in a desiccator containing saturated sodium chloride solution $(75 \% \mathrm{Rh})$. The desiccator was stored at $40^{\circ} \mathrm{C}$ for 3 months. At predetermined time intervals, the tablets were examined for hardness, FLT, TFT, drug content, and drug release.

\section{RESULTS AND DISCUSSION}

$\mathrm{RN}$ exhibited a $\mathrm{pH}$ dependent solubility phenomenon in different buffers. It shows maximum solubility in $0.1 \mathrm{~N} \mathrm{HCl}$, while the solubility was decreased as the $\mathrm{pH}$ increased.

\section{Drug-excipients interaction study}

DSC studies indicated a sharp endothermic peak at $120-125^{\circ} \mathrm{C}$ corresponding to its melting point, for pure RN (Fig. 1). No significant change in the position of this peak or broadening of peak in the thermogram of drug and excipient mixture was observed with respect to the thermogram of pure drug (Fig. 2). Hence, it can be concluded that the drug and excipients do not interact with each other.

Drug-polymer interactions were studied by fourier transform-infrared spectroscopy analysis. Fig. 3 showed the IR spectra of pure RN. The characteristic $\mathrm{CH}$ stretching, $\mathrm{NH}$ stretching of secondary amine, $\mathrm{C}=\mathrm{C}$ stretching, and $\mathrm{C}=\mathrm{O}$ stretching of pure drug was observed at $2964.47 \mathrm{~cm}-1,3357.73 \mathrm{~cm}-1,3025.35 \mathrm{~cm}-1$, and $1714.67 \mathrm{~cm}-1$. The characteristic peaks confirmed the structure of RN. The same peaks were also reported in the physical mixture (Fig. 4). Hence, it indicates the stable nature of drug in all formulations.

\section{Physical properties of tablets}

The tablets of RN were prepared by direct compression method using natural polymers (xanthan gum, guar gum). The data of physical parameters

Table 1: Composition of the ritonavir floating tablets

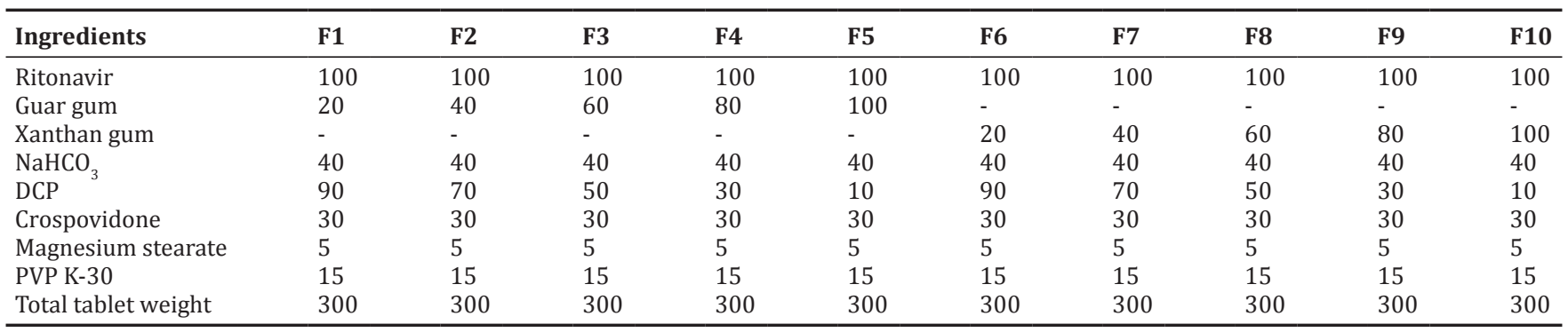

DCP: Di calcium phosphate, PVP: Polyvinylpyrrolidone 


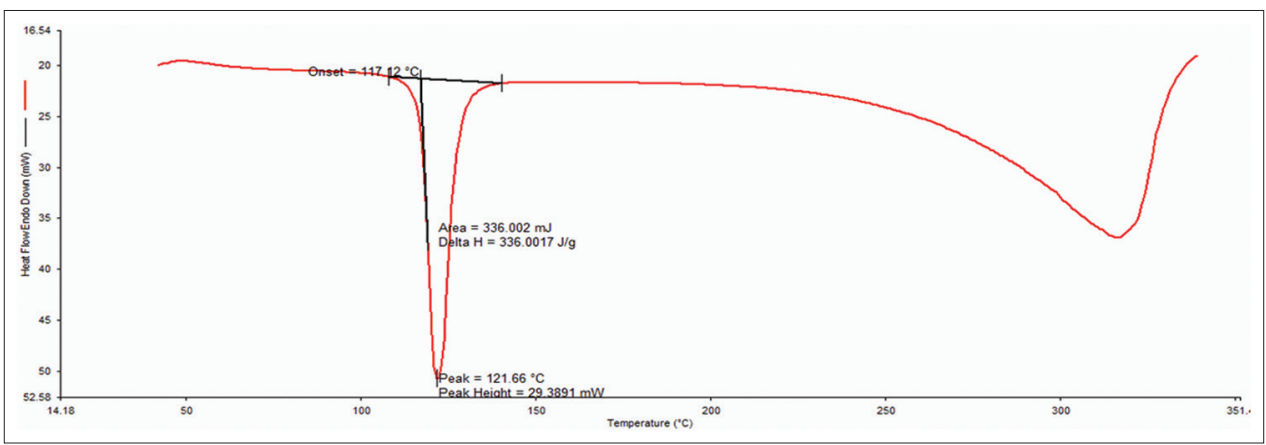

Fig. 1: Differential scanning calorimetry spectra for pure drug

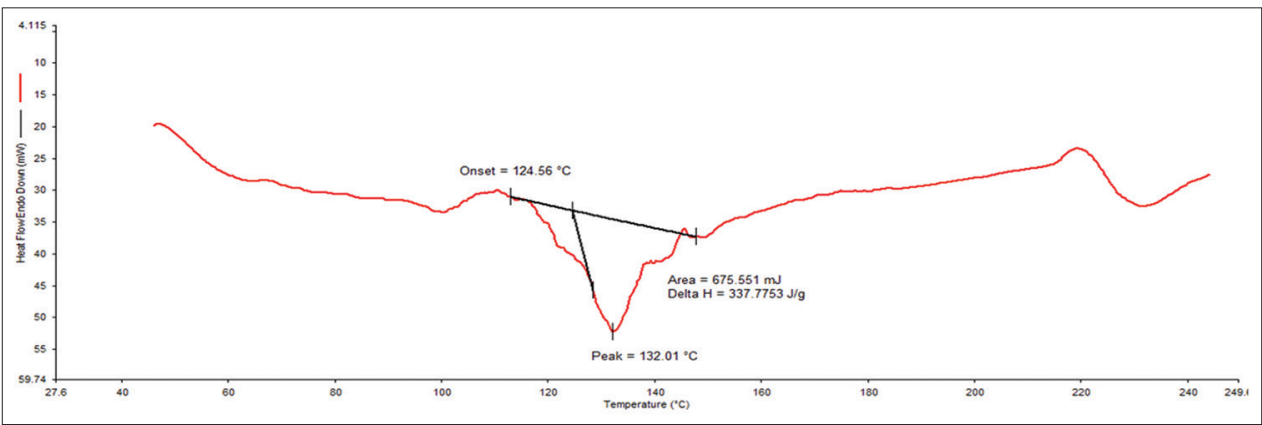

Fig. 2: Differential scanning calorimetry spectra for drug+excipients

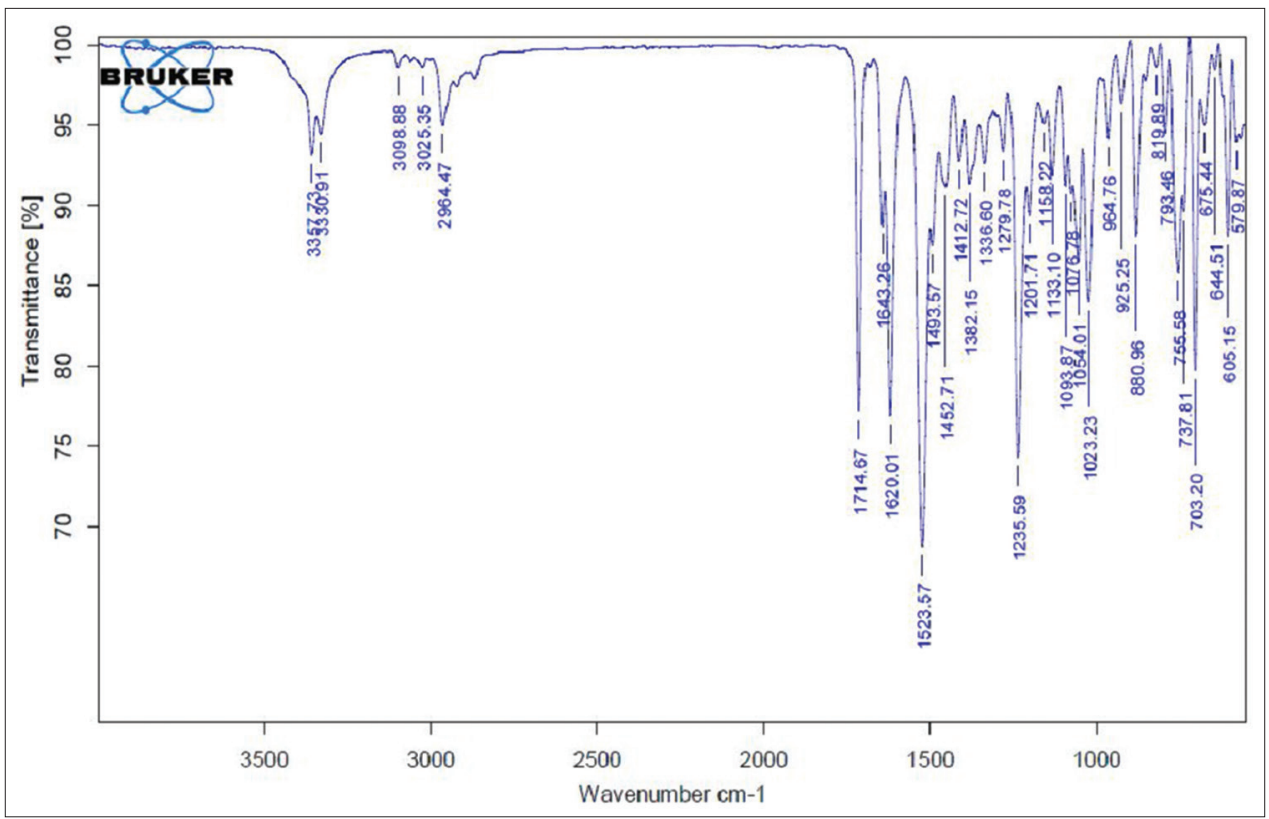

Fig. 3: Fourier-transform infrared spectra for pure drug

were presented in Table 2. All the tablet formulations showed acceptable physicochemical properties and complied with the pharmacopoeial specifications for weight variation, drug content and friability [20]. The physical evaluation of the tablets revealed uniform thickness and weight for all the tablets (evident from low SD values). The hardness values between 5 and $5.3 \mathrm{~kg} / \mathrm{cm}^{2}$ and low friability values (below $0.45 \%$ ) across all formulations indicated that the tablets had sufficient mechanical strength. The drug content uniformity studies revealed that drug content between $96.33 \pm 2.3 \%$ and $98.91 \pm 2.8 \%$ is acceptable.

\section{FLT and TFT}

In this study, sodium bicarbonate was used as a gas-generating agent to aid floating of tablets. The in vitro testing revealed the ability of most formulations to maintain buoyant for more than $12 \mathrm{hrs}$ (Table 2 and Fig. 5). As shown in Table 2, all the formulations floated with a lag time of $<1$ minute. The FLT of the formulations F1-F5 prepared with different concentrations of guar gum with constant sodium bicarbonate ratio, ranged from 15 to 35 seconds and that of formulations F6-F10, prepared with xanthan gum, ranged from 37 to 62 seconds had no significant effect. In all the formulations, as the concentration of sodium bicarbonate increased, the FLT was decreased [21] and TFT increased, but the difference in FLT was not statistically significant.

\section{In vitro release studies}

In vitro dissolution studies of all the formulations of RN tablets were conducted in $0.1 \mathrm{~N} \mathrm{HCl}(\mathrm{pH} \mathrm{1.2)}$. Formulations (F1-F5) were prepared 
Table 2: Physical parameters of gastroretentive tablets of ritonavir

\begin{tabular}{|c|c|c|c|c|c|c|c|c|}
\hline Formulation & $\begin{array}{l}\text { Weight } \\
\text { variation (mg) }\end{array}$ & $\begin{array}{l}\text { Hardness } \\
\left(\mathrm{kg} / \mathrm{cm}^{2}\right)\end{array}$ & Thickness (mm) & Friability (\%) & $\begin{array}{l}\text { Drug } \\
\text { content (\%) }\end{array}$ & FLT (seconds) & TFT (hrs) & $\begin{array}{l}\text { Drug } \\
\text { release (\%) }\end{array}$ \\
\hline $\mathrm{F} 1$ & 302 & $5.1 \pm 0.115$ & $3.5 \pm 0.05$ & 0.22 & 98.28 & $15 \pm 1$ & $>12$ & 99.56 \\
\hline F2 & 300 & $5.3 \pm 0.2$ & $3.5 \pm 0.08$ & 0.36 & 99.52 & $23 \pm 3$ & $>12$ & 97.95 \\
\hline F3 & 297 & $5.2 \pm 0.305$ & $3.5 \pm 0.05$ & 0.25 & 99.04 & $27 \pm 5$ & $>12$ & 80.05 \\
\hline F4 & 301 & $5.0 \pm 0.230$ & $3.5 \pm 0.08$ & 0.33 & 99.56 & $18 \pm 4$ & $>12$ & 99.96 \\
\hline F5 & 299 & $5.1 \pm 0.115$ & $3.5 \pm 0.05$ & 0.26 & 99.41 & $35 \pm 2$ & $>12$ & 97.98 \\
\hline F6 & 296 & $5.0 \pm 0.23$ & $3.5 \pm 0.05$ & 0.37 & 99.84 & $45 \pm 7$ & $>12$ & 89.20 \\
\hline F8 & 300 & $5.1 \pm 0.2$ & $3.5 \pm 0.03$ & 0.14 & 99.52 & $62 \pm 2$ & $>12$ & 66.65 \\
\hline F9 & 301 & $5.3 \pm 0.215$ & $3.5 \pm 0.04$ & 0.19 & 99.04 & $37 \pm 4$ & $>12$ & 98.32 \\
\hline F10 & 302 & $5.20 \pm 0.23$ & $3.5 \pm 0.08$ & 0.28 & 98.56 & $49 \pm 9$ & $>12$ & 84.19 \\
\hline
\end{tabular}

FLT: Floating lag time, TFT: Total floating time

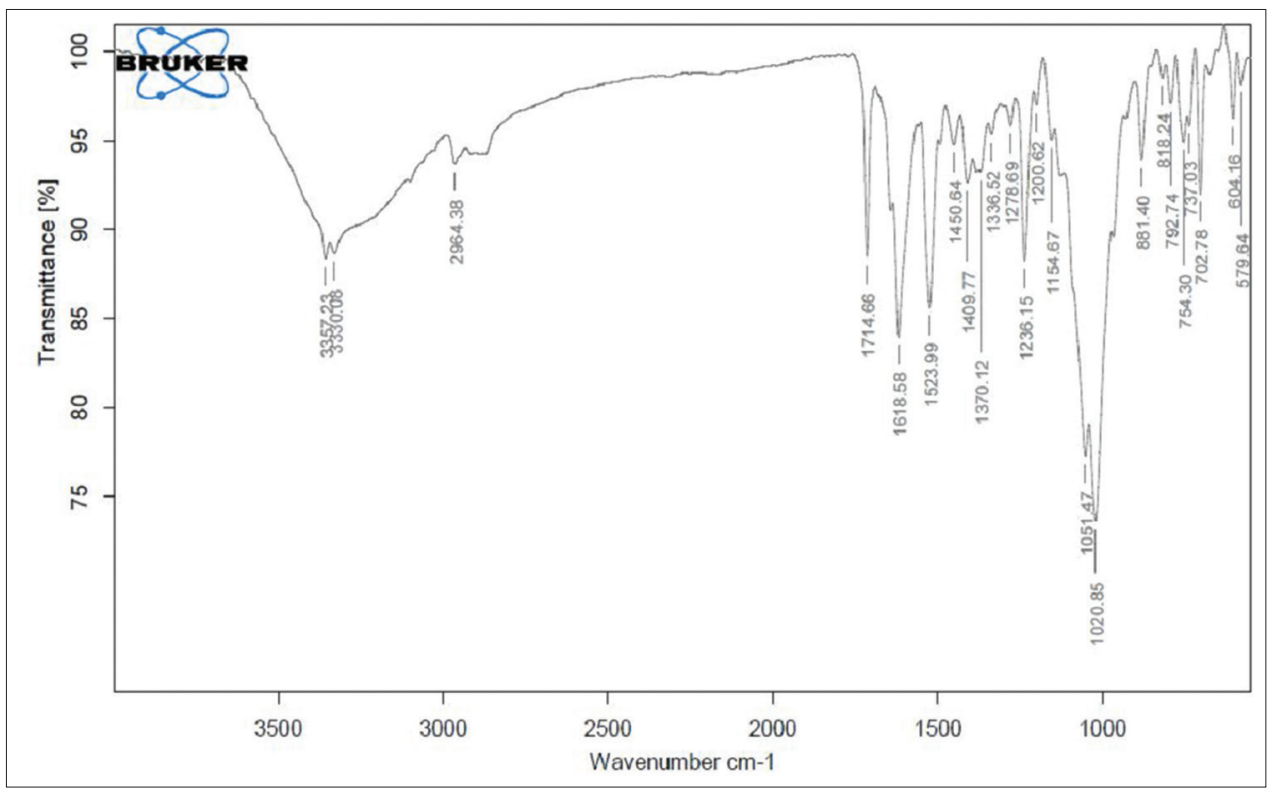

Fig. 4: Fourier-transform infrared spectra for pure drug+physical mixture
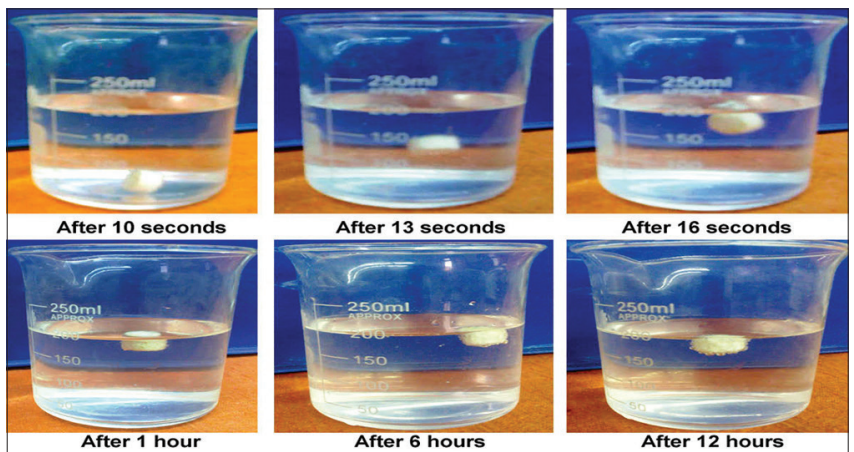

Fig. 5: Floating characteristics of ritonavir floating tablet

with varying concentrations of guar gum, and F6-F10 were prepared with varying concentrations of xanthan gum. The drug release profiles of the formulations, F1-F5 prepared with guar gum shown in Fig. 6. The effect of guar gum concentration on drug release was evaluated. As the concentration of guar gum was increased, the drug release from the floating tablets was significantly decreased [22]. The differences in the release might be due to the amount of gel layer formed on the surface of the tablets. If the polymer concentration is too low, a complete gel layer may not form resulting in a significant amount of drug being released too quickly or tablet may disintegrate [23].
The in vitro drug release studies revealed that formulations F1, F2, and F3 showed a release of $92.4,95.2$, and $96.7 \%$, respectively, in 6, 8, and $10 \mathrm{hrs}$ (Fig. 7). Formulation F4 showed maximum drug release of $98.5 \%$ in $12 \mathrm{hrs}$. The variation in drug release was due to different polymer concentrations in all the formulations. Formulations (F1-F3) were unable to sustain the drug release desired period of time. Formulation F4 met the needed theoretical drug release profile and floated with a lag time of 18 seconds. Formulation F5 failed to release the required drug profile. For these reasons, F4 was considered as the best formulation among all the five formulations of this series. The results were shown in Fig. 6. Drug release profiles of formulations F6-F10, composed of xanthan gum, are shown in Fig. 6.

The percentage of drug released from formulations F6, F7, and F8 was 86.8, 84.3, and 87.3, respectively, in 6,8 , and $10 \mathrm{hrs}$. This variation was considered to be due to different polymer concentrations in formulations. Further, these three formulations failed to meet the required theoretical drug release profile. Formulation F9 met the needed theoretical drug release profile and floated with a lag time of 37 seconds. Formulation F10 failed to release the required drug profile. For these reasons, F9 was considered as the best formulation among all the five formulations of this series. The results were shown in (Fig. 6). Data of the in vitro release of the optimized formulation were fit into different kinetic models to explain the release kinetics of RN from the floating tablets. The kinetic models used were a zero-order equation, first-order equation, Higuchi and KorsmeyerPeppas models (Table 3). Optimized formulation follows Higuchi 


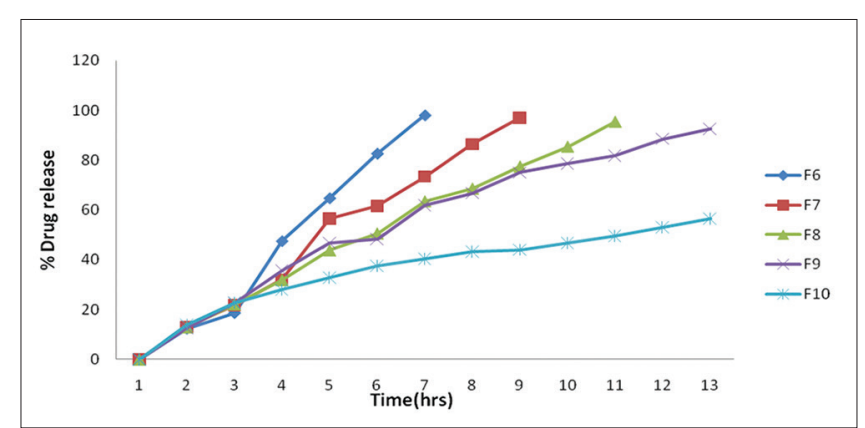

Fig. 6: Drug release profiles of ritonavir floating tablets composed of xanthan gum

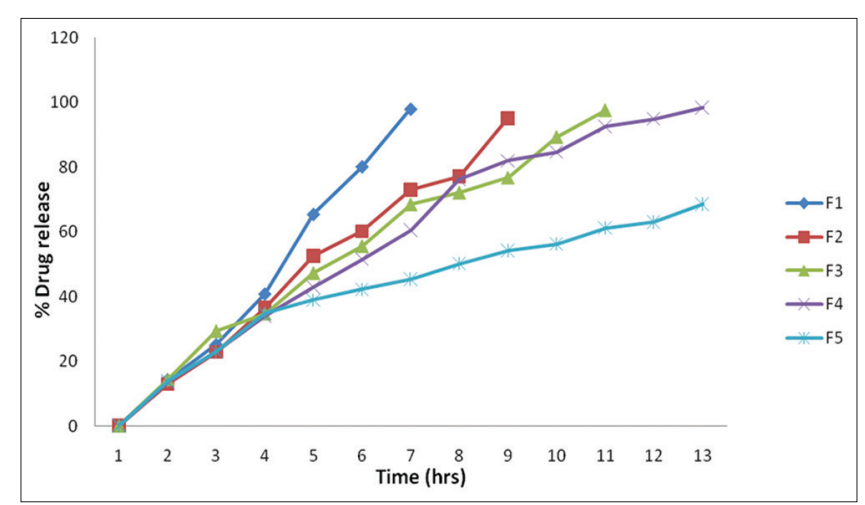

Fig. 7: Drug release profiles of ritonavir floating tablets composed of guar gum

Table 3: The correlation coefficient $\left(R^{2}\right)$ values for optimized formulation

\begin{tabular}{llll}
\hline Zero-order & First-order & Higuchi & Peppas \\
\hline 0.9815 & 0.7027 & 0.9953 & 0.8928 \\
\hline
\end{tabular}

Table 4: Stability studies optimized batch

\begin{tabular}{llll}
\hline Parameters & \multicolumn{2}{l}{ Storage conditions } & \\
\cline { 2 - 4 } & At 2-8 ${ }^{\circ} \mathbf{C}$ & $\begin{array}{l}\text { Room } \\
\text { temperature }\end{array}$ & At $\mathbf{4 0}^{\circ} \mathbf{C}$ \\
\hline \% cumulative drug release & 95.10 & 96.82 & 94.73 \\
Drug content uniformity (\%) & 99.13 & 99.35 & 98.46 \\
Color change & No & No & No \\
\hline
\end{tabular}

model compared to all other models. Optimized formulation (F4) was selected for stability study based on physical characters and in vitro drug release. The stability study was conducted for 3 months. No significant change was observed in the tablet hardness, FLT, TFT, and drug content or in vitro dissolution (Table 4). Hence that, it can be concluded that the formulation F4 was stable for 3 months under different storage conditions

\section{CONCLUSION}

RN floating tablets were successfully formulated by floating technique. The optimized formulation (F4) was selected on the basis of in vitro buoyancy and in vitro drug release. The addition of gel forming agent and gas generating agent was essential to achieve in vitro buoyancy. The results of the in vitro drug release and in vitro buoyancy study showed that the optimized formulation (F4) sustained the drug release $(98.47 \pm 0.71 \%)$ up to $12 \mathrm{hrs}$ and remained buoyant for $>12 \mathrm{hrs}$. Optimized formulation (F4) does not show any significant change in physical appearance, floating properties and drug release after storage at $40^{\circ} \mathrm{C} / 75 \% \mathrm{RH}$ and stable for 3 months.

\section{ACKNOWLEDGMENT}

The authors are thankful to AICTE (QIP) New Delhi and Principal, University College of Pharmaceutical Sciences, Kakatiya University, Warangal - 506009 , Telangana State, India, for the providing research facility.

\section{REFERENCES}

1. Streubel A, Siepmann J, Bodmeier R. Gastroretentive drug delivery systems. Expert Opin Drug Deliv 2006;3(2):217-33.

2. Streubel A, Siepmann J, Bodmeier R. Drug delivery to the upper small intestine window using gastroretentive technologies. Curr Opin Pharmacol 2006;6(5):501-8.

3. Rajak P, Bhattacharya A, Sharma N, Kataki MS, Rajkumari A. Gastro-retentive floating drug delivery system - An approach in gastroretentive drug delivery. Int J Pharm Pharm Sci 2011;3(4):9-16.

4. Groning R, Heun G. Oral dosage forms with controlled gastrointestinal transit. Drug Dev Indust Pharm 1984;1:527-39.

5. Fujimori J, Machida Y, Tanaka S, Nagai T. Effect of magnetically controlled gastric residence of sustained release tablets on bioavailability of acetaminophen. Int J Pharm 1995;119:47-55.

6. Dhaliwal S, Jain S, Singh HP, Tiwary AK. Mucoadhesive microspheres for gastroretentive delivery of acyclovir: In vitro and in vivo evaluation. AAPS J 2008;10(2):322-30.

7. Deshpande AA, Shah NH, Rhodes CT, Malick W. Development of a novel controlled-release system for gastric retention. Pharm Res 1997;14(6):815-9.

8. Baumgartner S, Kristl J, Vrecer F, Vodopivec P, Zorko B. Optimisation of floating matrix tablets and evaluation of their gastric residence time. Int J Pharm 2000;195(1-2):125-35.

9. Devereux JE, Newton JM, Short MB. The influence of density on the gastrointestinal transit of pellets. J Pharm Pharmacol 1990;42(7):500-1.

10. Pistell PJ, Gupta S, Knight AG, Domingue M, Uranga RM, Ingram DK, et al. Metabolic and neurologic consequences of chronic lopinavir/ritonavir administration to C57BL/6 mice. Antiviral Res 2010;88(3):334-42.

11. Law D, Schmitt EA, Marsh KC, Everitt EA, Wang W, Fort JJ, et al. Ritonavir-PEG 8000 amorphous solid dispersions: In vitro and in vivo evaluations. J Pharm Sci 2004;93(3):563-70.

12. Law D, Krill SL, Schmitt EA, Fort JJ, Qiu Y, Wang W, et al. Physicochemical consideration in the preparation of amorphous ritonavir-poly(ethylene glycol) 8000 solid dispersions. J Pharm Sci 2001;90(8):1015-26.

13. Pharmacopoeial Convention Inc. United States Pharmacopoeia. Asian XXXI Edition. Rockville, MD: Pharmacopoeial Convention Inc.; 2008. p. 3200-1.

14. Williams GC, Sinko PJ. Oral absorption of the HIV protease inhibitors: A current update. Adv Drug Deliv Rev 1999;39(1-3):211-38.

15. Kim RB, From MF, Wandel C, Leake B, Wood AJ, Roden DM. The drug transporter P-glycoprotein limits oral absorption and brain entry of HIV-1 protease inhibitors. J Clin Invest 1998;101(2):289-94.

16. Aungst BJ. P-glycoprotein, secretory transport, and other barriers to the oral delivery of anti-HIV drugs. Adv Drug Deliv Rev 1999;39(13): $105-16$.

17. Higuchi T. Mechanism of sustained-action medication. Theoretical analysis of rate of release of solid drugs dispersed in solid matrices. J Pharm Sci 1963;52:1145-9.

18. Korsmeyer RW, Gurny R, Docler E, Buri P, Peppas NA. Mechanism of solute release from porous hydrophilic polymers. Int J Pharm $1983 ; 15(1): 25-35$.

19. Matthews BR. Regulatory aspects of stability testing in Europe. Drug Dev Ind Pharm 1999;25(7):831-56.

20. Pharmacopoeial Convention Inc. United States Pharmacopeia 27 and National Formulary 22. Asian Edition. Rockville, MD: Pharmacopeial Convention, Inc.; 2004.

21. Poonuru RS, Rao GC. Spatio temporal release of lamotrigine by buoyant gastroretentive drug delivery: Development and evaluation. Int J Pharm Pharm Sci 2014;6(4):604-10.

22. Chandira RM, Bhowmik D, Bhattacharjee C, Jayakar B. Formulation and evaluation of gastroretentive drug delivery system of gastroprokinetic drug itopride hydrochloride. Int J Pharm Pharm Sci 2010;1(1):53-65.

23. Cheong LW, Heng PW, Wong LF. Relationship between polymer viscosity and drug release from a matrix system. Pharm Res 1992;9(11):1510-4. 